\title{
Bottom-up effects of endophytic Beauveria bassiana on multitrophic interactions between the cotton aphid, Aphis gossypii, and its natural enemies in melon
}

\author{
N. González-Mas ${ }^{1}$ - M. Cuenca-Medina ${ }^{1}$ ·F. Gutiérrez-Sánchez ${ }^{1} \cdot$ E. Quesada-Moraga ${ }^{1}$
}

Received: 2 December 2018 / Accepted: 18 February 2019 / Published online: 25 February 2019

(c) The Author(s) 2019

\begin{abstract}
Entomopathogenic fungi are now known to have an endophytic capacity that induces a wide range of changes in the composition of plant nutrients and/or defensive compounds. These changes could influence interactions between the plant and higher trophic levels. In this study, we evaluated the predation/parasitism efficacy of larvae of the lacewing, Chrysoperla carnea, and the braconid parasitoid, Aphidius colemani, when offered aphids that had been challenged by the entomopathogenic fungus Beauveria bassiana. Aphids were either inoculated directly with a fungal suspension (lacewing bioassay only) or had been feeding on melon plants endophytically colonized by $B$. bassiana. Our results indicate that $B$. bassiana application did not significantly influence the number of aphid prey consumed by lacewings, or the time took them to consume each aphid. In a choice bioassay, $C$. carnea larvae preferred to feed on aphids reared on B. bassiana-colonized plants compared with control plants. In another choice assay, the number of aphids parasitized by $A$. colemani and their sex ratio were not influenced by whether the aphids had been feeding on B. bassiana-colonized plants or not. Our findings support the hypothesis that endophytic entomopathogenic fungi can be used in combination with other natural enemies, such as predators and parasitoids, in Integrated Pest Management programmes.
\end{abstract}

Keywords Chrysoperla carnea $\cdot$ Aphidius colemani $\cdot$ Predator $\cdot$ Parasitoid $\cdot$ Entomopathogenic fungus $\cdot$ Endophyte $\cdot$ IPM

\section{Key message}

- The predatory and parasitic efficacy of lacewings and parasitoids on aphids were unaffected when these aphids had been feeding on plants endophytically colonized by the entomopathogenic fungus Beauveria bassiana.

- When given a choice, lacewings did show a preference for predating aphids that were feeding on B. bassianacolonized plants compared with control plants.

Communicated by M. Traugott.

E. Quesada-Moraga

cr2qumoe@uco.es

1 Departamento de Ciencias y Recursos Agrícolas y Forestales, ETSIAM, Universidad de Córdoba, Campus Rabanales, Edificio C4 Celestino Mutis, 14071 Córdoba, Spain
- These findings suggest that predators and parasitoids can be used together in Integrated Pest Management programmes with endophytic entomopathogenic fungi.

\section{Introduction}

Integrated Pest Management (IPM) is an interdisciplinary approach for control of agricultural pest populations that is regulated in the European Union Member States (Directive 2009/128/EC) and in the United States (U.S. Code $\S$ 136r-1). In principal, IPM uses optimal combinations of the most suitable techniques and methods available for controlling a given pest. The aim is to retain pest populations below damage thresholds while simultaneously reducing reliance on chemical pesticides. In this way, the development of insecticide resistance is minimized and hazards to non-targets, including humans and the environment, are reduced (Stern et al. 1959; Smith 1978; Metcalf and Luckmann 1994; FAO 2018). Biological control agents, such as entomophagous arthropods (predators and parasitoids) and 
entomopathogenic microorganisms, are environmentally friendly products that can contribute to IPM strategies and, as such, there is an increasing demand for natural pest control products (Zehnder et al. 2007; Lacey and Shapiro-Ilan 2008; Abrol 2014).

Entomopathogenic fungi are a diverse assemblage of species that infect insect and mite hosts. They are present in almost all terrestrial ecosystems and habitats and play many different ecological roles (Lovett and St. Leger 2017). They have been found in the soil, the phylloplane and most recently as plant endophytes and as rhizosphere-competent microorganisms (Quesada-Moraga et al. 2006; Meyling and Eilenberg 2007; Vega et al. 2009; Vega 2018).

The combined use of entomopathogenic fungi and entomophagous arthropods within IPM strategies has been explored. This takes advantage of the contact action of the fungi and the ability of predators and parasitoids to search for their prey which, together, could ensure that fewer pests escape treatment (Baverstock et al. 2010; Ren et al. 2010). It is likely that combinations of various biological control agents could be additive with respect to suppression of pest populations (Wraight 2003). However, intraguild and multitrophic interactions should be considered when multiple biological control agents are applied simultaneously or sequentially after planned time intervals (Martins et al. 2014). Indeed, several studies have examined the safety and effectiveness of combinations of entomopathogenic fungi and other components of biological control such as predators, parasitoids and nematodes (Roy and Pell 2000; Acevedo et al. 2007; Labbé et al. 2009; Ansari et al. 2010; Martins et al. 2014).

The recent discovery that entomopathogenic fungi can be endophytic with a new systemic biological control role raises concerns about previously unconsidered interactions with beneficial and non-target organisms, including other biological control agents (Jaber and Ownley 2018; Vega 2018). Endophytic plant colonization by entomopathogenic fungi induces a wide range of changes in the composition and quantity of plant nutrients and/or defensive compounds within the plant; this has implications for the quality of the plant as a food source for herbivores (Gualandi et al. 2014; Shrivastava et al. 2015; Sánchez-Rodríguez et al. 2015; Liao et al. 2017; Raya-Díaz et al. 2017; Krell et al. 2018). These changes may lead to a cascade of positive or negative changes in the life history characteristics and behaviour of herbivores and their interactions with natural enemies. Effects on third trophic level (i.e. natural enemies) have been reported in other microorganism-plant associations, such as those with mycorrhizal fungi (Gange et al. 2003; Guerrieri et al. 2004; Hempel et al. 2009), plant growth-promoting rhizobacteria (PGPR) (D'Alessandro et al. 2014; Gadhave et al. 2016) and other fungal endophytes in grass (Bultman et al. 1997, 2012; de Sassi et al. 2006; Härri et al. 2008).
Likewise, it has been reported that endophytic colonization by entomopathogenic fungi induces analogous effects in members of the third trophic level such as parasitoids (Akutse et al. 2014; Gathage et al. 2016; Jaber and Araj 2018). However, it remains unknown whether such colonization caused any effect on predators. Moreover, there is only one study on the combined use of endophytic entomopathogenic fungi and entomophagous arthropods for aphid control and only considered parasitoids (Jaber and Araj 2018).

In the current study, we evaluated whether the efficacy of aphid control using plants endophytically colonized by an entomopathogenic fungus would be affected if combined with predators and parasitoids. Specifically, we used the endophytic Beauveria bassiana isolate EABb 01/33$\mathrm{Su}$ along with the most widespread and important natural enemies of the cotton aphid, Aphis gossypii (Hemiptera; Aphididae), i.e. the generalist predator Chrysoperla carnea (Coleoptera; Chrysopidae) and the braconid parasitoid Aphidius colemani (Hymenoptera; Braconidae). We used predator-prey bioassays and choice tests to compare the efficacy and behaviour of $C$. carnea larvae when offered aphids that had either been sprayed directly with a suspension of $B$. bassiana conidia or had been feeding on melon plants endophytically colonized by $B$. bassiana. We also evaluated the behaviour and reproductive success of the aphid parasitoid, A. colemani, when offered a choice between aphids that had been feeding on melon plants endophytically colonized with B. bassiana and control aphids.

\section{Materials and methods}

\section{Study organisms}

Melon seeds (Cucumis melo L. var. Galia) were surfacesterilized in $2 \%$ sodium hypochlorite (Sigma-Aldrich, MO, USA) for $2 \mathrm{~min}$, rinsed twice with sterile Mili-Q water and dried in a laminar-flow hood under sterile conditions. The soil substrate (Floragard, Germany) was also sterilized twice in an autoclave for $20 \mathrm{~min}$ at $121{ }^{\circ} \mathrm{C}$ with a 24-h interval between each sterilization process. Surface-sterilized seeds were germinated in $9 \times 9 \mathrm{~cm}$ pots containing a mixture of equal parts of vermiculite (No. 3, Asfaltex S.A., Barcelona, Spain) and the sterilized soil substrate. Germinated seeds were maintained in an environmental chamber under controlled conditions: $25 \pm 2{ }^{\circ} \mathrm{C}$ and a 16-h light: 8 -h dark regime. A nutritional complex of 20:20:20 (N:P:K) Nutrichem 60 fertilizer (Miller Chemical \& Fertilizer Corp., PE, USA) was added to the irrigation water at a rate of $1 \mathrm{~g}^{-1}$ three times a week.

Aphis gossypii population was provided by the Institute of Agricultural Sciences (ICA) CSIC (Madrid, Spain) and then reared for several generations in the laboratory. Aphids 
were reared in cages on melon plants in an environmental growth chamber under controlled conditions of $25 \pm 2{ }^{\circ} \mathrm{C}$, a 16-h light: 8-h dark regime and 70\% RH.

Beauveria bassiana isolate EABb 01/33-Su was used in all the bioassays. The endophytic ability of this isolate when inoculated onto melon plants had been demonstrated previously (Resquín-Romero et al. 2016), as had its ability to cause mortality in sap-sucking insects when endophytic (Garrido-Jurado et al. 2016; González-Mas and QuesadaMoraga 2017). EABb 01/33-Su was originally isolated from soil from El Bosque (Cádiz) and deposited in the University of Córdoba Entomopathogenic Fungi Collection, Córdoba, Spain. Nucleotide sequences for the ITS and mtDNA intergenic regions of EABb 01/33-Su can be found in the GenBank database (EF115310 and FJ972969 for the ITS region; FJ973025 for intergenic region nad3-atp9; and FJ972914 for the intergenic region atp6-rns).

For all bioassays, isolate $\mathrm{EABb} 01 / 33$-Su was grown on potato dextrose agar (PDA) in Petri dishes for 15 days at $25^{\circ} \mathrm{C}$ in darkness. A cellophane film was placed on the agar prior to inoculation to prevent nutrients transferring to the conidial suspension at the time of harvest. Conidial suspensions were prepared by scraping conidia from the dishes into an aqueous sterile solution of $0.01 \%$ Tween 80 . The resulting conidial suspension was filtered through several layers of sterile cheesecloth to remove mycelia, and sonicated for 5 min to homogenize the inoculum. Conidial concentrations were determined using a haemocytometer and appropriate dilutions made in $0.01 \%$ Tween 80 to achieve a concentration of $10^{8}$ conidia $\mathrm{ml}^{-1}$ for experiments. Prior to experimentation conidial viability was determined on liquid CzapekDox broth plus $1 \%(\mathrm{w} / \mathrm{v})$ yeast extract medium and only suspensions with $>97.0 \%$ germination after $24 \mathrm{~h}$ were used.

Chrysoperla carnea larvae and A. colemani mummies (pupae) were supplied by Koppert Biological Systems (Almeria, Spain).

\section{Predation efficacy of C. carnea offered healthy or $B$. bassiana-infected aphids}

Ten groups of newly emerged apterous adult aphids (24-72 h since last moult), each containing ten individuals, were collected from the rearing cages into Petri dishes $(60 \mathrm{~mm} \emptyset)$ with a hole sealed with fine-mesh netting to provide air-circulation, using a camel-hair brush. Each group was immersed in separate $5 \mathrm{ml}$ aliquots of either a $1 \times 10^{8}$ conidia $\mathrm{ml}^{-1}$ suspension of $B$. bassiana $(n=$ five groups), or a $0.01 \%$ sterile solution of Tween 80 in the case of the control ( $n=$ five groups) and then removed with the aid of a camel-hair brush. Each group of aphids was incubated in the absence of food in Petri dishes $(60 \mathrm{~mm} \emptyset)$ for $24 \mathrm{~h}$ under the same controlled conditions as described previously for aphid rearing. At the same time, ten lacewings were placed individually in Petri dishes $(60 \mathrm{~mm} \varnothing)$ and incubated under the same aphid controlled conditions in the absence of food for $24 \mathrm{~h}$ prior to the assay.

Aphids ( $24 \mathrm{~h}$ after being treated) were offered ad libitum to the lacewings one by one. Once an aphid was completely consumed, it was automatically replaced with a new one. The number of aphids consumed and the time required for consumption of each one were recorded over a period of $4 \mathrm{~h}$. The entire experiment was done twice, each time using fresh fungal inoculum, aphids and lacewings.

\section{Predation efficacy of $C$. carnea offered control aphids or aphids reared on B. bassiana-colonized melon plants}

Replicate melon plants were grown, as described previously, to the four-leaf stage. Leaves of these plants were sprayed either with conidial suspensions of $B$. bassiana ( $n=$ ten) or with a sterile solution of $0.01 \%$ Tween 80 (control; $n=$ ten). Specifically, two leaves per treatment plant were each sprayed with $1 \mathrm{ml}$ of fungal suspension using an aerograph 27085 (piston compressor of $231 \mathrm{~min}^{-1}, 15-50$ PSI and a $0.3 \mathrm{~mm}$ nozzle diameter, China). The remaining plant leaves were covered with a transparent plastic sheet prior to spraying to prevent them from being inoculated. After spraying, the entire plant was enclosed in clean plastic sheeting for $24 \mathrm{~h}$ to promote fungal growth. Control plants were treated similarly. Plants were incubated in an environmental chamber at $25 \pm 2{ }^{\circ} \mathrm{C}, 16$-h light: 8-h dark regime and $70 \% \mathrm{RH}$ for $48 \mathrm{~h}$; unsprayed leaves were covered with plastic bags to avoid any contamination between sprayed and unsprayed leaves. Ten newly emerged apterous adult aphids (24-72 h after last moult) were transferred, using a camelhair brush, to a non-sprayed leaf in each of the B. bassianatreated plants, and to a non-sprayed leaf in each of the control plants. Aphids were confined to the leaves in clip cages and incubated at $25 \pm 2{ }^{\circ} \mathrm{C}, 16$-h light: 8 -h dark regime and $70 \%$ RH for 6 days. Each clip cage had a hole sealed with fine-mesh netting to provide air-circulation. Aphids were then removed from the leaves and offered to the lacewings as described in the previous section. The number of aphids consumed and the time required for consumption of each one were recorded over a period of $4 \mathrm{~h}$. The entire experiment was done twice, each time using fresh fungal inoculum, plants, aphids and lacewings.

\section{Predatory behaviour of $C$. carnea offered a choice of aphids reared on B. bassiana-colonized or control melon plants}

Lacewing predatory behaviour was observed in a choice assay based on ten replicates of endophytically colonized and control leaves. To achieve this, endophytically colonized 
and control plants were produced as described previously. However, in this case, only five apterous adult aphids were transferred to each non-sprayed leaf in both $B$. bassianacolonized and control melon plants $48 \mathrm{~h}$ after spraying. Aphids were confined in a clip cage for 6 days under the same abiotic conditions as described previously. Three of the adult aphids were transferred to another aphid-free $B$. bassiana-colonized (not directly sprayed) or control leaf on the same plant, and these aphids were used in the experiment. This was done to ensure that the number of aphids presented to the predator on each leaf was the same in each replicate and thus prey density would not affect predator choice. Without detaching leaves from mother plants, one non-sprayed leaf (bearing three aphids) from a B. bassianacolonized plant and one from a control plant (also bearing three aphids) were placed through two holes made in a Petri dish arena $(150 \mathrm{~mm} \times 15 \mathrm{~mm})$; the arena was designed such that the leaves were $7 \mathrm{~cm}$ apart from each other. One lacewing was introduced into each of the ten arenas at a central position (Fig. 1) and its behaviour observed over a period of $3 \mathrm{~h}$ using a point sampling procedure, with a final observation $24 \mathrm{~h}$ after initiation. At each sampling interval (every hour), the activity of the lacewings was recorded as follows: walking on the control leaf, feeding on an aphid on the control leaf, walking on the $B$. bassiana-colonized leaf, feeding on an aphid on the B. bassiana-colonized leaf, or exploring throughout the arena (i.e. walking but on neither of the leaves). Final position of the lacewing after $24 \mathrm{~h}$ was also recorded. The entire experiment was done on two occasions, each time using fresh fungal inoculum, plants, aphids and lacewings.

\section{Oviposition preference and development of $A$. colemani offered a choice of aphids reared on $B$. bassiana-colonized or control melon plants}

Control and endophytically colonized melon plants were established as described previously $(n=10)$. Once endophytic colonization was established ( $48 \mathrm{~h}$ after spraying) (Resquín-Romero et al. 2016), a group of ten secondinstar A. gossypii aphids (a stage suitable for parasitization by A. colemani; Sampaio et al. 2008) was transferred onto one of the non-sprayed leaves on each replicate plant using a fine camel-hair brush, and enclosed within a clip cage ( $2 \mathrm{~cm}$ in diameter; $1 \mathrm{~cm}$ high). Aphids were allowed to feed on the plants for a further $72 \mathrm{~h}$ before the experiment was started. After this period, some of them had become 3rd instars but were still suitable hosts for the parasitoid. While the aphids were developing, the A. colemani mummies were divided into 20 groups of 100 in lidless Petri dishes $(60 \mathrm{~mm} \varnothing)$ and each group placed into a mesh cage $(350 \mathrm{~mm} \times 250 \mathrm{~mm} \times 200 \mathrm{~mm})$. Cages were incubated in an environmental chamber at $25{ }^{\circ} \mathrm{C}$ and 16 -h light: 8-h dark regime until the parasitoids emerged $(24-48 \mathrm{~h})$. Cotton wool soaked with a $50 \%$ honey: water solution was provided as a food resource in each cage for the emerging adults. Five days after the parasitoids began emerging, unsprayed leaves bearing aphids (clip cages removed) from one endophytically colonized plant and one control plant, were introduced to each cage of parasitoids. Each leaf remained attached to the mother plant (which remained outside the cage) and was introduce through sealable access holes in the cage sides. The areas of cage in contact with the plant were lined with foam rubber to avoid damaging the leaves (Fig. 2). Parasitoid females present (4-5 days old and mated) were allowed to parasitize aphids for $24 \mathrm{~h}$; they choose between aphids on endophytically colonized or control leaves. After this time the leaves, still attached to the mother plant, were removed from the cages and entire plants incubated in an environmental chamber under suitable conditions for parasitoid development. Endophytically colonized plants were held separately from the control plants to ensure there was no transfer of aphids between endophytically colonized and control plants. The number of parasitoid mummies that developed were counted and removed from each plant daily until no more were produced. The mummies removed were incubated in

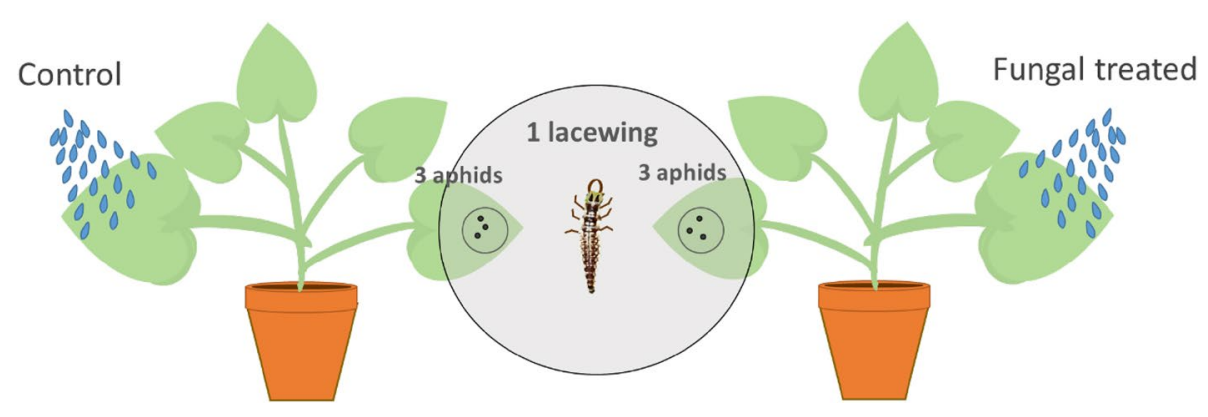

Fig. 1 Design of an arena for the lacewing choice bioassay. The setup consists of one large Petri dish $(150 \mathrm{~mm} \times 15 \mathrm{~mm})$ with two holes (diameter $25 \mathrm{~mm}$ each) in the bottom and covered by the lid. The area in contact with the plant was lined with foam rubber to avoid dam- aging the leaves. Lacewings could choose between an unsprayed leaf from a $B$. bassiana-colonized plant and a leaf from the control plant. Position on control/treatment plant or off the plant, feeding activity and final position at the end of the experiment were recorded 


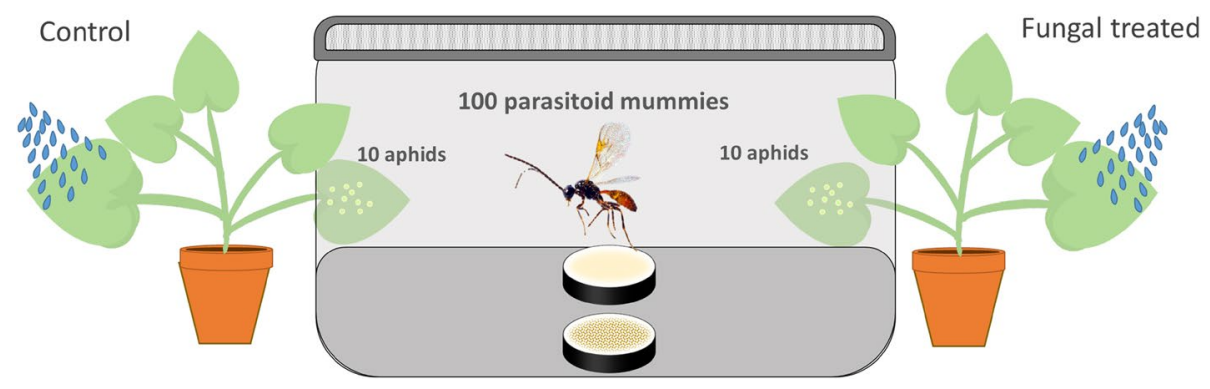

Fig. 2 Design of the cage used for the parasitoid choice bioassay. The set-up consists of one large cage $(350 \mathrm{~mm} \times 250 \mathrm{~mm} \times 200 \mathrm{~mm})$ with two holes at the sides and covered by a mesh lid. The area in contact with the plant was lined with foam rubber to avoid leaf damage. Para- sitoids chose between aphids feeding on a non-sprayed leaf endophytically colonized by $B$. bassiana or aphids feeding on a control leaf. Final number of mummies was recorded

of aphid prey bioassay (endophytically colonized leaves vs control leaves).

Aphid prey mortality data based on lacewing consumption times were subjected to Kaplan-Meier survival analysis (Kaplan and Meier 1958) to calculate Average Survival Time (AST; i.e. average consumption time) values in minutes and compared by the Log-rank test using SPSS $19.0^{\circledR}$ software for Windows.

The percentage of mummified aphids, parasitoid emergence, and parasitoids that emerged as either female or male were subjected to the Kruskal-Wallis nonparametric test using SPSS $19.0^{\circledR}$ software for Windows.

When there was no statistically significant difference in the results from the two occasions on which each experiment was done the data were pooled, analysed together, and presented as a single graph.

\section{Results}

\section{Predation efficacy of $C$. carnea offered healthy aphids or aphids infected with B. bassiana as prey}

Predation efficacy of $C$. carnea was affected by fungal treatment of the aphids neither in the number of prey consumed nor in the number of prey offered during the observation period $\left(\chi_{1 \mathrm{df}}^{2}=0.20, p=0.66\right.$ and $\chi_{1 \mathrm{df}}^{2}=0.35$, $p=0.56$, respectively) (Fig. 3). In addition, there was no difference between treatment and control in the mean time employed by each lacewing to consume its aphid prey $($ Control AST $=130.39 \pm 15.07 \mathrm{~min}$; Treatment $\mathrm{AST}=126.12 \pm 12.34 \mathrm{~min}$ ) (Fig. 4).

\section{Predation efficacy of $C$. carnea on control aphids or aphids that had been reared on melon plants endophytically colonized by $B$. bassiana}

lacewings were analysed using a generalized linear model with a Poisson distribution link function. A Pearson's correlation and Chi-square $(p \leq 0.05)$ analysis were performed to evaluate the predatory behaviour of $C$. carnea in the choice
No B. bassiana outgrowth was observed in any of the control samples examined or from the plated rinse water. In 


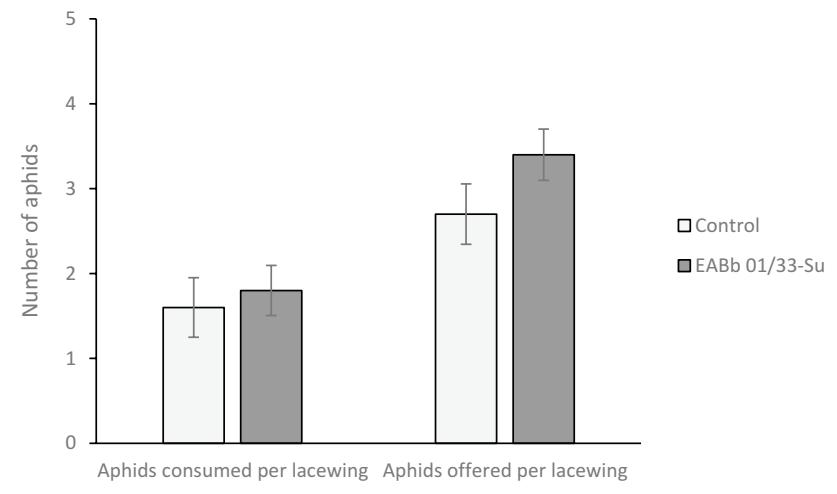

Fig. 3 Number of aphid prey (mean \pm SE) consumed and number offered during the observation period. Prey were either aphids immersed in $B$. bassiana suspension $\left(1 \times 10^{8}\right.$ conidia $\left.\mathrm{ml}^{-1}\right)$ or sterile $0.01 \%$ Tween 80 (controls) $24 \mathrm{~h}$ prior to experiment. Asterisks indicate significant differences between control and treatment $\left(\chi_{1 \mathrm{df}}^{2}\right.$, $p<0.05)$

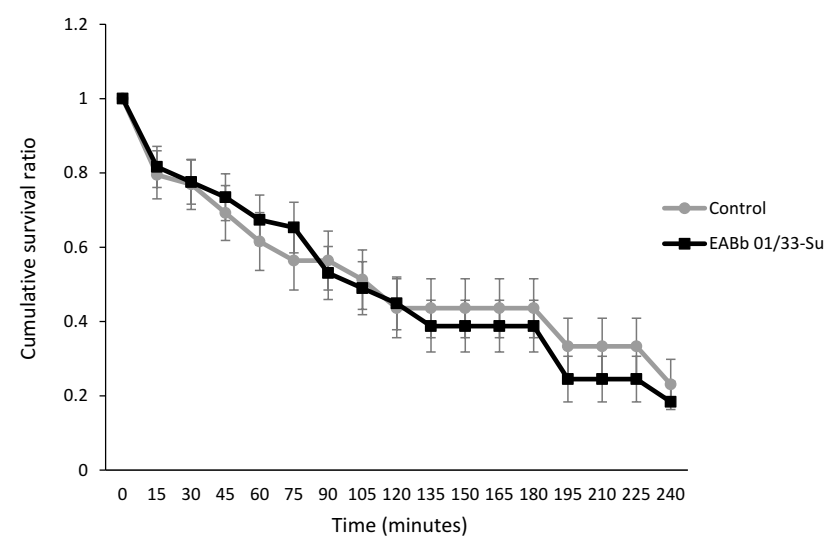

Fig. 4 Cumulative proportion of A. gossypii prey (either immersed in B. bassiana suspension $\left[1 \times 10^{8}\right.$ conidia $\left.\mathrm{ml}^{-1}\right]$ or sterile $0.01 \%$ Tween 80 (controls) $24 \mathrm{~h}$ prior to experiment) that were offered to lacewings and survived until the end of the observation period. Data are expressed as the mean $\pm \mathrm{SE}$

contrast, all the leaves from inoculated plants had been colonized endophytically by $B$. bassiana. They were observed higher levels of colonization in sprayed leaves $(93.33 \pm 3.10$ colonies per leaf fragment $)$ compared with non-sprayed leaves on the same plant $(24.00 \pm 9.81$ colonies per leaf fragment).

Predation efficacy of $C$. carnea was not affected when feeding on aphids reared on $B$. bassiana-colonized plants compared with the control, either in the number of prey consumed or the number of prey offered during the observation period $\left(\chi_{1 \mathrm{df}}^{2}=0.53, p=0.47\right.$ and $\chi_{1 \mathrm{df}}^{2}=0.22, p=0.66$, respectively) (Fig. 5). However, there was an increase (though statistically insignificant) in the mean time employed by each lacewing to consume its aphid prey when the aphid was reared on B. bassiana-colonized plants compared with

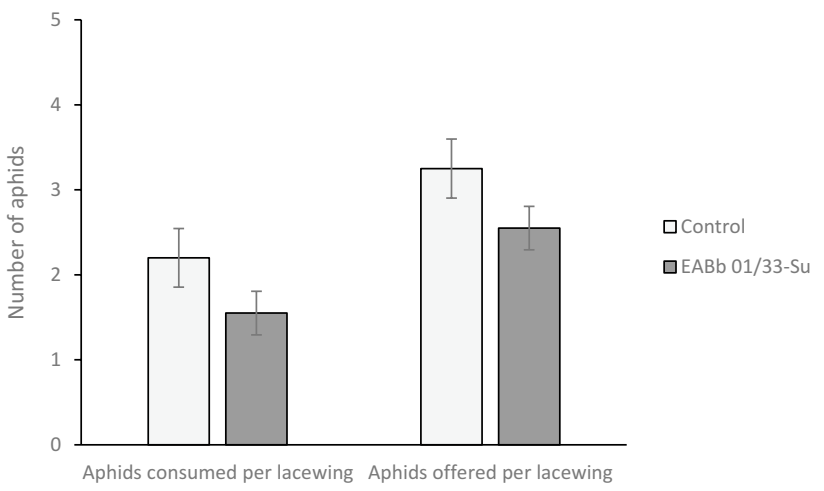

Fig. 5 Number of aphid prey (mean \pm SE) consumed and number offered during the observation period. Prey were aphids that were either fed for $140 \mathrm{~h}$ on $B$. bassiana-colonized melon plants, or fed for $140 \mathrm{~h}$ on control plants. Asterisks indicate significant differences between control and treatment $\left(\chi_{1 \mathrm{df}}^{2}, p<0.05\right)$

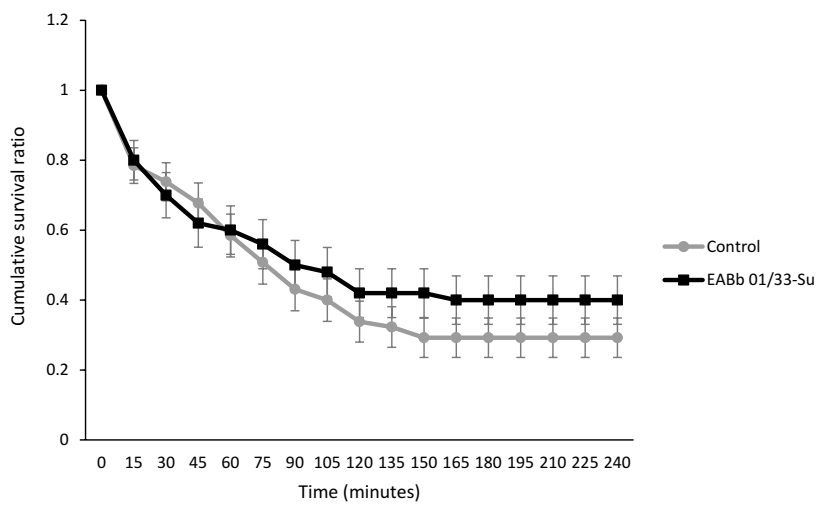

Fig. 6 Cumulative proportion of A. gossypii prey (either fed on $B$. bassiana-colonized plants or control plants) that were offered to lacewings and survived until the end of the observation period. Data are expressed as the mean $\pm \mathrm{SE}$

the control (Control AST $=113.08 \pm 10.99 \mathrm{~min}$; Treatment $\mathrm{AST}=127.80 \pm 13.72 \mathrm{~min}$ ) (Fig. 6).

\section{Predatory behaviour of $C$. carnea when offered a choice of aphid prey feeding either on leaves endophytically colonized by $B$. bassiana or control leaves}

No B. bassiana outgrowth was observed in any of the control samples examined or from the plated rinse water. In contrast, all the leaves from inoculated plants had been colonized endophytically by $B$. bassiana. The level of endophytic colonization of non-sprayed leaves was $36.11 \pm 4.86$ colonies per leaf fragment compared with $95.50 \pm 2.11$ colonies per leaf fragment for sprayed leaves.

The choice assays revealed a significant preference of the predators for aphids feeding on B. bassiana 
endophytically colonized plants compared with control plants $\left(\chi_{1 \mathrm{df}}^{2}=9.29 ; p=0.00\right)\left(\mathrm{chi}^{2}\right.$ test, $\left.\alpha=0.05\right)$. Initially, we observed that the lacewings were mainly exploring throughout the experimental arena and not on the leaves. However, the longer the exposure time, the higher the number of lacewings preferring endophytically colonized leaves to prey on aphids (Fig. 7).

\section{Oviposition preference and development of $A$. colemani when offered a choice of aphid prey feeding either on leaves endophytically colonized by $B$. bassiana or control leaves}

No $B$. bassiana outgrowth was observed in any of the control samples examined or from the plated rinse water. In contrast, all the leaves from inoculated plants had been colonized endophytically by $B$. bassiana. The level of endophytic colonization of unsprayed leaves was $43.62 \pm 2.86$ colonies per leaf fragment compared with $93.50 \pm 2.04$ colonies per leaf fragment for sprayed leaves.

No significant differences were detected in parasitoid preference for aphids feeding on B. bassiana-colonized plants compared to the controls. There was no significant difference in the number of mummies recovered from aphids reared on $B$. bassiana-colonized plants compared with controls $(H=0.40 ; p=0.53)$, mummy development time $(H=2.17 ; p=0.15)$ or the sex ratio (females $H=0.00$; $p=0.96$; males $H=0.82 ; p=0.37$ ) (Fig. 8).

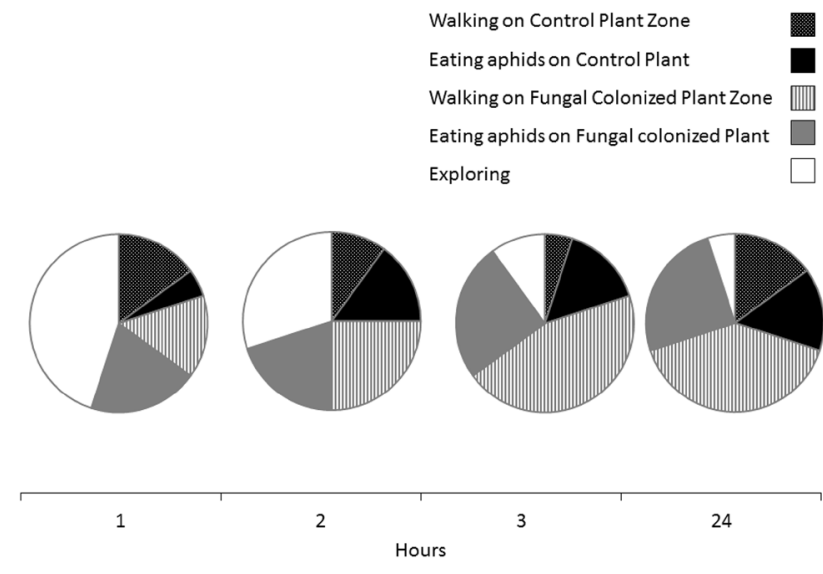

Fig. 7 Percentage of $C$. carnea larvae choosing aphids feeding either on a $B$. bassiana-colonized plant or a control plant. Circles denote the proportion of lacewings (a) walking on the B. bassiana-colonized leaf, (b) feeding on aphids on the B. bassiana-colonized leaf, (c) walking on the control leaf, (d) feeding on aphids on the control leaf, and (e) exploring the arena but not walking on either of the leaves. Lacewing behaviour was observed once every hour for three hours and the final establishment was recorded at $24 \mathrm{~h}$

\section{Discussion}

Several studies have evaluated the lethal and sub-lethal effects of entomopathogenic fungi on predators and parasitoids when applied directly as fungal suspensions. In general, these effects are strongly related to fungal dosage and the sequence of treatments. Lower fungal dosages and application of the arthropod natural enemy first reduced negative effects of entomopathogenic fungi on ladybird beetles (James et al. 1995; Pingel and Lewis 1996; Todorova et al. 1996; Roy and Pell 2000; Smith and Krischik 2000; Pell and Vandenberg 2002; Roy et al. 2008), lacewings (C. carnea) (Portilla et al. 2017), and several aphid parasitoid species (Brodeur and Rosenheim 2000; Mesquita and Lacey 2001; Kim et al. 2005; Aqueel and Leather 2013; Oreste et al. 2016; Shrestha et al. 2017). Likewise, infection of prey and the time interval between fungal application and predator/parasitoid release may also affect the number of aphids consumed by the predator or the number of parasitoid mummies that may develop (Mesquita and Lacey 2001; Aqueel and Leather 2013; IbarraCortés et al. 2018).

In our study, lacewing prey consumption rate and the time spent to consume each aphid were not significantly affected by whether the aphid prey had been directly exposed to B. bassiana or not. There was a trend for prey consumption rate to decrease and consumption time to increase on endophytically colonized plants compared with controls. Fungal infection could reduce the nutritional quality of aphids leading to 'poor quality prey' which could account for a slight increase in prey consumption rate (Pell et al. 1997).

In general, previous studies have shown that treatments with entomopathogenic fungi should be considered as a low risk to predators and parasitoids. However, there are contradictory reports concerning the effect of entomopathogenic fungal treatments on the efficacy of predators and parasitoids. Avoidance of fungal-infected hosts and fungus-contaminated leaf surfaces by predators has been demonstrated (Pell and Vandenberg 2002; Meyling and Pell 2006), but also reports of compatibility between ladybirds (Coccinella septempunctata and Harmonia axyridis) consuming aphids at a late stage of Pandora neoaphidis and Neozygites fresenii infection (Pell et al. 1997; Roy et al. 1998, 2008; Simelane et al. 2008); between $C$. carnea feeding on Metarhizium brunneum-treated Spodoptera littoralis larvae (Ríos-Moreno et al. 2018); and between the parasitoid Aphidius ervi ovipositing in aphids infected with Pandora neoaphidis (Baverstock et al. 2005). In the last example, overall aphid control was enhanced, but the number of parasitoid mummies recovered was reduced in the presence of fungal infection in the aphid hosts 
A
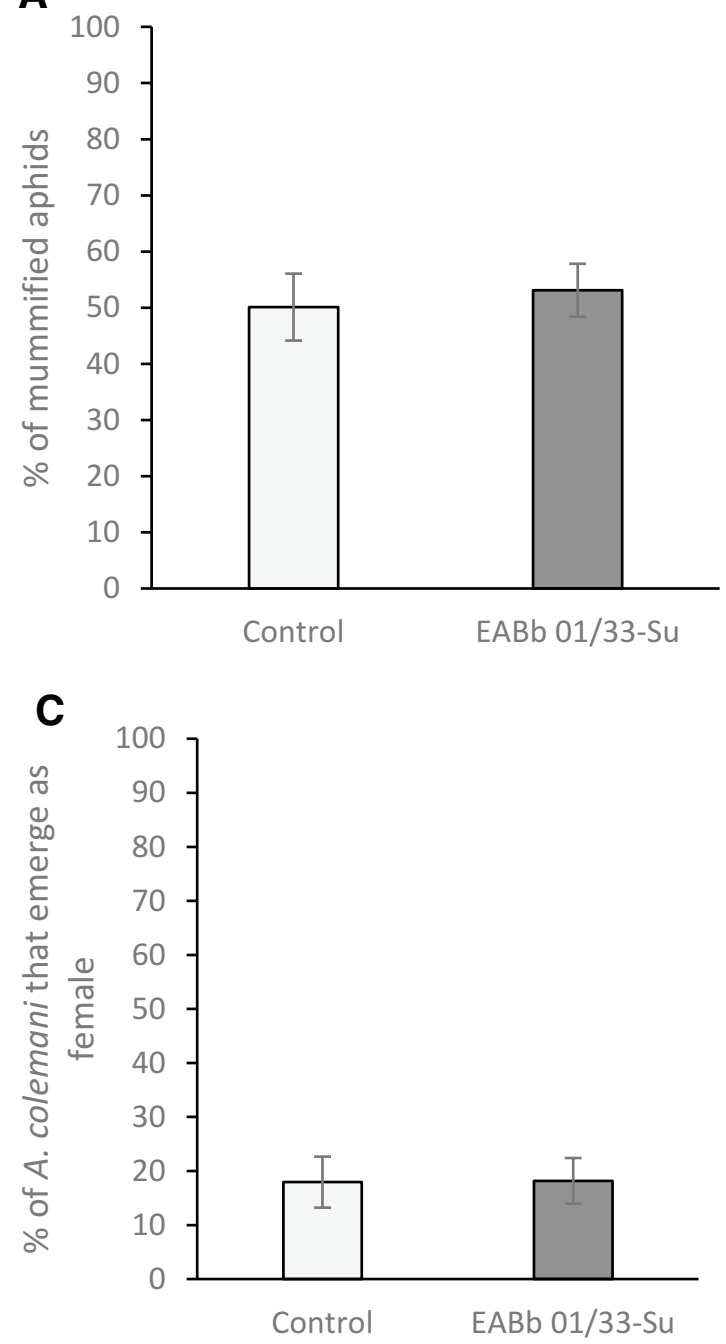

Fig. 8 Parameters of parasitoid fitness when offered a choice of parasitizing aphids feeding on $B$. bassiana-colonized leaves or aphids feeding on control leaves. a Percentage of mummified aphids, b percentage of F1 A. colemani emerging as adults, c percentage of F1 A.

(Baverstock et al. 2005). In our study, lacewings did not always entirely consume living aphids infected with $B$. bassiana after direct spraying, which suggests avoidance of the infected parts of the aphid by the lacewing, which would increase lacewing safety. This has been reported previously in $C$. carnea feeding on living M. brunneuminfected S. littoralis larvae (Ríos-Moreno et al. 2018).

Recently, it has been demonstrated that spraying of entomopathogenic fungal conidia onto plants can lead to transient endophytic colonization of the plant that enhanced treatment efficacy (Garrido-Jurado et al. 2016; ResquínRomero et al. 2016). In these scenarios, the fungal propagules were not in direct contact with entomophagous insects and they did not consider that natural enemies may feed on endophytically exposed prey or hosts (Garrido-Jurado
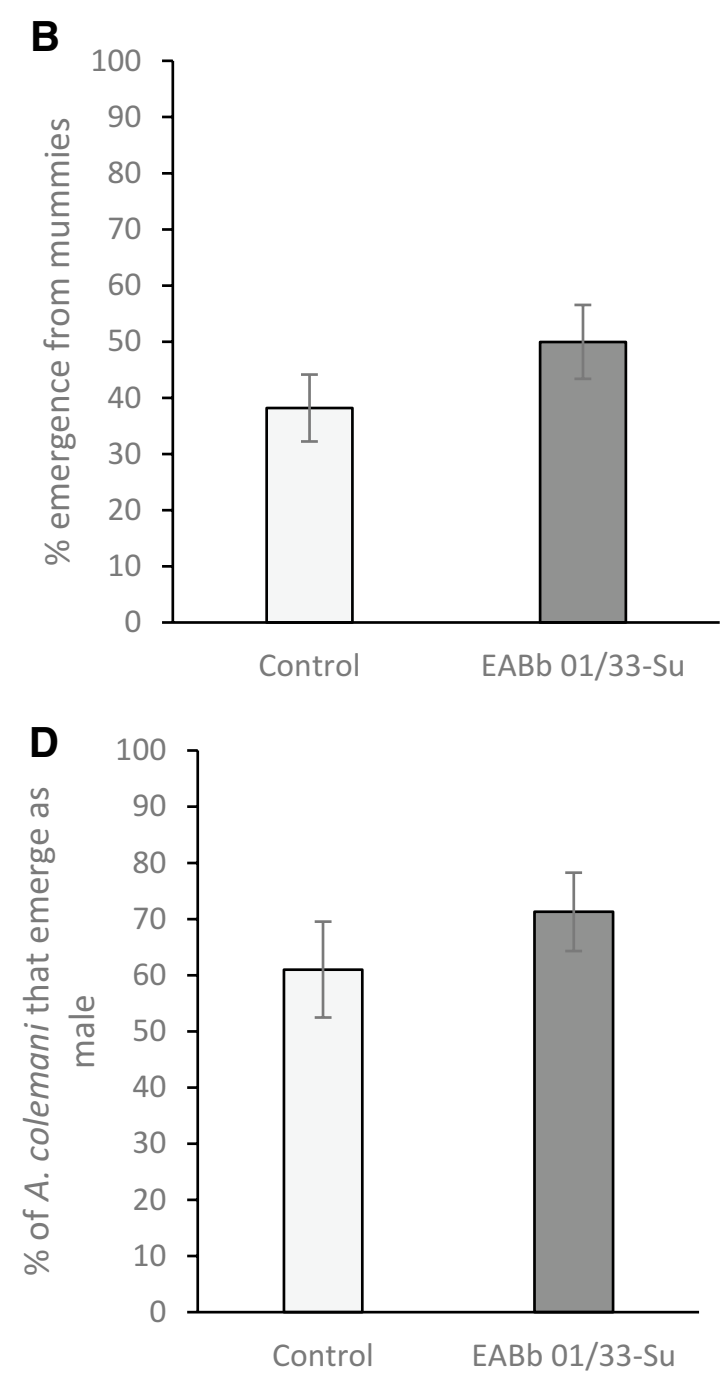

colemani that were female and $\mathbf{d}$ percentage of F1 A. colemani that were male. Asterisks indicate significant differences between control and treatment $\left(\chi_{1 \mathrm{df}}^{2}, p<0.05\right)$

et al. 2016). Furthermore, endophytic colonization by entomopathogenic fungi could influence plant signalling pathways in an analogous way to arbuscular mycorrhizal symbiosis, plant growth-promoting microorganisms like the rhizobacteria, and fungal endophytes of grasses, which may also alter insect population dynamics at higher trophic levels (Bultman et al. 1997, 2012; Barker and Addison 1996; Gange et al. 2003, 2012; Guerrieri et al. 2004; Hempel et al. 2009; Gadhave et al. 2016).

The present study indicated no significant effect of endophytically colonized plants on $C$. carnea predatory behaviour, although there was a trend for a decrease in aphid consumption rate and an increase in consumption time for aphids from $B$. bassiana-colonized plants compared with controls. However, the choice assay revealed a significant 
preference of the predators for aphids feeding on B. bassiana endophytically colonized plants. Feeding site location, plant foraging activity, mate location, oviposition site selection and detection of natural enemies are mediated by chemical cues (Dicke and Grostal 2001; Bruce et al. 2005; Sigsgaard 2005; Xu and Turlings 2018). Endophytic colonization by $B$. bassiana may not only alter the characteristics of plantemitted volatiles, but it may also improve the nutritional quality of the host plant for herbivores by reducing the aphid immune response (i.e. altering aphid symbionts), which may lead to higher predator attraction to aphids feeding on endophytically colonized plants (de Sassi et al. 2006; Polin et al. 2015; Shrivastava et al. 2015; Sánchez-Rodríguez et al. 2015; Liao et al. 2017; Krell et al. 2018). However, further research is needed to unravel the potential role of endophytic entomopathogenic fungi in governing trophic interactions between plants, pests and their natural enemies.

Our results agree with previous studies that have investigated the effect of endophytic entomopathogenic fungi on parasitoids; there was no significant effect on developmental time and percentage female (Akutse et al. 2014; Jaber and Araj 2018; Gathage et al. 2016). Likewise, Akutse et al. (2014) found no significant differences in terms of parasitism rates of the parasitoids Phaedrotoma scabriventris and Diglyphus isaea, when they parasitized 2nd and 3rd instar larvae of the pea leafminer Liriomyza huidobrensis, which had been reared on control and B. bassiana-colonized broad bean plants.

Equally, Gathage et al. (2016) carried out field trials to study the effect of seed inoculation with B. bassiana on six associated parasitoid species (Opius dissitus, Phaedrotoma scabriventris, Diglyphus isaea Walker, Neochrysocharis formosa, Hemiptarsenus varicornis and Halticoptera arduine) of the pea leafminer under field conditions. They found no significant differences in parasitoid emergence from pupae formed in B. bassiana-colonized and control plants.

Apart from that, Jaber and Araj (2018) investigated the effect of the endophytic colonization of sweet pepper plants by the fungal entomopathogens $B$. bassiana and $M$ brunneum on the parasitism of the green peach aphid Myzus persicae by Aphidius colemani under greenhouse conditions. They observed no differences in development time, percentage female, and adult longevity of the aphid parasitoid Aphidius colemani progenies among inoculated and control plants.

Therefore, all of these findings support the strategy that entomopathogenic fungal sprays can be used in combination with other natural enemies such as predators and parasitoids in IPM programmes. In particular, our results support the combined use of endophytic entomopathogenic fungi and entomophagous insects in aphid IPM programmes. The bottom-up effects of endophytically colonized plants are a low risk for predators and parasitoids. However, further research is needed to unravel the possible mechanisms involved in changes in prey or host selection.

\section{Author contribution statement}

EQM and NGM conceived and designed the study. NGM, MCM and FGS did the experiments. NGM, MCM and FGS analysed the data. EQM and NGM wrote the manuscript. All authors read and approved the manuscript before submission.

Acknowledgements Funding was provided by the Spanish Ministry of Economy and Competitivity via grant AGL2016-80483-R 'Interacciones multitróficas reguladas por hongos entomopatógenos para una protección de cultivos sostenible'. We also thank Pablo ValverdeGarcía for his assistance with the statistical analysis.

Open Access This article is distributed under the terms of the Creative Commons Attribution 4.0 International License (http://creativeco mmons.org/licenses/by/4.0/), which permits unrestricted use, distribution, and reproduction in any medium, provided you give appropriate credit to the original author(s) and the source, provide a link to the Creative Commons license, and indicate if changes were made.

\section{References}

Abrol DP (2014) Integrated pest management: current concepts and ecological perspective. Academic Press, San Diego

Acevedo JP, Samuels RI, Machado I, Dolinski C (2007) Interactions between isolates of the entomopathogenic fungus Metarhizium anisopliae and the entomopathogenic nematode Heterorhabditis bacteriophora JPM4 during infection of the sugar cane borer Diatraea saccharalis (Lepidoptera: Pyralidae). J Invertebr Pathol 96:187-192

Akutse KS, Fiaboe KKM, Van den Berg J, Ekesi S, Maniania NK (2014) Effects of endophyte colonization of Vicia faba (Fabaceae) plants on the life-history of leafminer parasitoids Phaedrotoma scabriventris (Hymenoptera: Braconidae) and Diglyphus isaea (Hymenoptera: Eulophidae). PLoS ONE 9:e109965

Ansari MA, Shah FA, Butt TM (2010) The entomopathogenic nematode Steinernema kraussei and Metarhizium anisopliae work synergistically in controlling overwintering larvae of the black vine weevil, Otiorhynchus sulcatus, in strawberry growbags. Biocontrol Sci Technol 20:99-105

Aqueel MA, Leather SR (2013) Virulence of Verticillium lecanii (Z.) against cereal aphids; does timing of infection affect the performance of parasitoids and predators? Pest Man Sci 69:493-498

Barker GM, Addison PJ (1996) Influence of clavicipitaceous endophyte infection in ryegrass on development of the parasitoid Microctonus hyperodae Loan. (Hymenoptera: Braconidae) in Listronotus bonariensis (Kuschel) (Coleoptera: Curculionidae). Biol Control 3:281-287

Baverstock J, Alderson PG, Pell JK (2005) Influence of the aphid pathogen Pandora neoaphidis on the foraging behaviour of the aphid parasitoid Aphidius ervi. Ecol Entomol 6:665-672

Baverstock J, Roy HE, Pell JK (2010) Entomopathogenic fungi and insect behavior: from unsuspecting hosts to targeted vectors. Biocontrol 55:89-102 
Brodeur J, Rosenheim JA (2000) Intraguild interactions in aphid parasitoids. Entomol Exp Appl 97:93-108

Bruce TJA, Wadhams LJ, Woodcock CM (2005) Insect host location: a volatile situation. Trends Plant Sci 10:269-274

Bultman TL, Borowicz KL, Schneble RM, Coudron TA, Bush LP (1997) Effect of a fungal endophyte on the growth and survival of two Euplectrus parasitoids. Oikos 78:170-176

Bultman TL, Aguilera A, Sullivan TJ (2012) Influence of fungal isolates infecting tall fescue on multitrophic interactions. Fungal Ecol 5:372-378

D’Alessandro M, Erb M, Ton J, Brandenburg A, Karlen D, Zopfi J, Turlings TCJ (2014) Volatiles produced by soil-borne endophytic bacteria increase plant pathogen resistance and affect tritrophic interactions. Plant Cell Environ 37:813-826

de Sassi C, Mueller CB, Krauss J (2006) Fungal plant endosymbionts alter life history and reproductive success of aphid predators. Proc R Soc Lond B 273:1301-1306

Dicke M, Grostal P (2001) Chemical detection of natural enemies by arthropods: an ecological perspective. Annu Rev Ecol Evol Syst 32:1-23

FAO (2018) More about IPM. http://www.fao.org/agriculture/crops/ thematic-sitemap/theme/pests/ipm/more-ipm/en/. Accessed 24 Sept 2018

Gadhave KR, Finch P, Gibson TM, Gange AC (2016) Plant growthpromoting Bacillus suppress Brevicoryne brassicae field infestation and trigger density-dependent and density-independent natural enemy responses. J Pest Sci 89:985-992

Gange AC, Brown VK, Aplin DM (2003) Multitrophic links between arbuscular mycorrhizal fungi and insect parasitoids. Ecol Lett 6:1051-1055

Gange AC, Eschen R, Schroeder V (2012) The soil microbial community and plant foliar defences against insects. In: Iason GR, Dicke M, Hartley SE (eds) The ecology of plant secondary metabolites: from genes to global processes. Cambridge University Press, UK, pp 170-188

Garrido-Jurado I, Resquín-Romero G, Amarilla SP, Ríos-Moreno A, Carrasco L, Quesada-Moraga E (2016) Transient endophytic colonization of melon plants by entomopathogenic fungi after foliar application for the control of Bemisia tabaci Gennadius (Hemiptera: Aleyrodidae). J Pest Sci 90:319-330

Gathage JW, Lagat ZO, Fiaboe KKM, Akutse KS, Ekesi S, Maniania NK (2016) Prospects of fungal endophytes in the control of Liriomyza leafminer flies in common bean Phaseolus vulgaris under field conditions. Biocontrol 61:741-753

González-Mas N, Quesada-Moraga E (2017) Effect of plants endophytically colonised by entomopathogenic fungi on aphids. IOBC-WPRS Bull 124:149-151

Gualandi RJ Jr, Auge RM, Kopsell DA, Ownley BH, Chen F, Toler HD, Dee MM, Gwinn KD (2014) Fungal mutualists enhance growth and phytochemical content in Echinacea purpurea. Symbiosis 63:111-121

Guerrieri E, Lingua G, Digilio MC, Massa N, Graziella Berta G (2004) Do interactions between plant roots and the rhizosphere affects parasitoid behaviour? Ecol Entomol 29:753-756

Härri SA, Krauss J, Mueller CB (2008) Natural enemies act faster than endophytic fungi in population control of cereal aphids. JAE 77:605-611

Hempel S, Stein C, Unsicker SB, Renker C, Auge H, Weisser WW, Buscot F (2009) Specific bottom-up effects of arbuscular mycorrhizal fungi across a plant-herbivore-parasitoid system. Oecologia 160:267-277

Ibarra-Cortés KH, Gonzalez-Hernandez H, Guzman-Franco AW, Ortega-Arenas LD, Villanueva-Jimenez JA, Robles-Bermudez A (2018) Interactions between entomopathogenic fungi and Tamarixia radiata (Hymenoptera: Eulophidae) in Diaphorina citri (Hemiptera: Liviidae) populations under laboratory conditions. J Pest Sci 91:373-384

Jaber LR, Araj SE (2018) Interactions among endophytic fungal entomopathogens (Ascomycota: Hypocreales), the green peach aphid Myzus persicae Sulzer (Homoptera: Aphididae), and the aphid endoparasitoid Aphidius colemani Viereck (Hymenoptera: Braconidae). Biol Control 116:53-61

Jaber LR, Ownley BH (2018) Can we use entomopathogenic fungi as endophytes for dual biological control of insect pests and plant pathogens? Biol Control 116:36-45

James RR, Shaffer BT, Croft B, Lighthart B (1995) Field evaluation of Beauveria bassiana: its persistence and effects on the pea aphid and a non-target coccinellid in alfalfa. Biocontrol Sci Technol 5:425-437

Kaplan EL, Meier P (1958) Nonparametric estimation from incomplete observations. J Am Stat Assoc 53:457-481

Kim JJ, Kim KC, Roberts DW (2005) Impact of the entomopathogenic fungus Verticillium lecanii on development of an aphid parasitoid, Aphidius colemani. J Invertebr Pathol 88:254-256

Krell V, Unger S, Jakobs-Schoenwandt D, Patel AV (2018) Endophytic Metarhizium brunneum mitigates nutrient deficits in potat and improves plant productivity and vitality. Fungal Ecol 34:43-49

Labbé RM, Gillespie DR, Cloutier C, Brodeur J (2009) Compatibility of an entomopathogenic fungus with a predator and a parasitoid in the biological control of greenhouse whitefly. Biocontrol Sci Technol 19:429-446

Lacey LA, Shapiro-Ilan DI (2008) Microbial control of insect pests in temperate orchard systems: potential for incorporation into IPM. Annu Rev Entomol 53:121-144

Liao X, Lovett B, Fang W, St. Leger RJ (2017) Metarhizium robertsii produces indole-3-acetic acid, which promotes root growth in Arabidopsis and enhances virulence to insects. Microbiology 163:980-991

Lovett B, St. Leger R (2017) The Insect Pathogens. In: Heitman J, Howlett B, Crous P, Stukenbrock E, James T, Gow N (eds) The fungal kingdom. ASM Press, Washington, DC, pp 925-943

Martins ICF, Silva JR, Alencar DCC, Silva KP, Cividanes FJ, Duarte RT, Agostini LT, Polanczyk RA (2014) Interactions between the entomopathogenic fungi Beauveria bassiana (Ascomycota: Hypocreales) and the aphid parasitoid Diaeretiella rapae (Hymenoptera: Braconidae) on Myzus persicae (Hemiptera: Aphididae). J Econ Entomol 107:933-938

Mesquita ALM, Lacey LA (2001) Interactions among entomopathogenic fungus Paecilomyces fumosoroseus (Deuteromycotina Hyphomycetes), the parasitoid Aphelinus asychis (Hymenoptera: Aphelinidae) and their aphis host. Biol Control 22:51-59

Metcalf RL, Luckmann WH (1994) Introduction to insect pest management. Wiley Interscience, New York

Meyling N, Eilenberg J (2007) Ecology of the entomopathogenic fungi Beauveria bassiana and Metarhizium anisopliae in temperate agroecosystems: potential for conservation biological control. Biol Control 43:145-155

Meyling NV, Pell JK (2006) Detection and avoidance of an entomopathogenic fungus by a generalist insect predator. Ecol Entomol 31:162-171

Oreste M, Bubici G, Poliseno M, Tarasco E (2016) Effect of Beauveria bassiana and Metarhizium anisopliae on the Trialeurodes vaporariorum-Encarsia formosa system. J Pest Sci 89:153-160

Pell JK, Vandenberg JD (2002) Interactions among the aphid Diuraphis noxia, the entomopathogenic fungus Paecilomyces fumosoroseus and the coccinellid Hippodamia convergens. Biocontrol Sci Technol 12:217-224

Pell JK, Pluke R, Clark SJ, Kenward MG, Alderson PG (1997) Interactions between two aphid natural enemies, the entomopathogeic fungus Erynia neoaphidis Remaudiere \& 
Hennebert (Zygomycetes: Entomophthorales) and the predatory beetle Coccinella septempunctata L (Coleoptera: Coccinellidae). J Invertebr Pathol 69:261-268

Pingel RL, Lewis LC (1996) The fungus Beauveria bassiana (Balsamo) Vuillemin in a corn ecosystem: its effect on the insect predator Coleomegilla maculata De Geer. Biol Control 6:137-141

Polin S, Le Gallic J-F, Simon J-C, Tsuchida T, Outreman Y (2015) Conditional reduction of predation risk associated with a facultative symbiont in an Insect. PLoS ONE 10:e0143728

Portilla M, Snodgrass G, Luttrell R (2017) Lethal and sub-lethal effects of Beauveria bassiana (Cordycipitaceae) strain NI8 on Chrysoperla rufilabris (Neuroptera: Chrysopidae). Fla Entomol 100:627-633

Quesada-Moraga E, Landa BB, Munoz-Ledesma J, Jimenez-Diaz RM, Santiago Alvarez C (2006) Endophytic colonisation of opium poppy, Papaver somniferum, by an entomopathogenic Beauveria bassiana strain. Mycopathologia 161:323-329

Raya-Díaz S, Sánchez-Rodríguez AR, Segura-Fernández JM, del Campillo MDC, Quesada-Moraga E (2017) Entomopathogenic fungi-based mechanisms for improved Fe nutrition in sorghum plants grown on calcareous substrates. PLoS ONE 12:e185903

Ren SX, Ali S, Huang Z, Wu JH (2010) Lecanicillium muscarium as microbial insecticide against whitefly and its interaction with other natural enemies. In: Mendez-Vilasn A (ed) Current research, technology and education topics in applied microbiology and microbial biotechnology. Formatex, Spain, pp 339-348

Resquín-Romero G, Garrido-Jurado I, Delso C, Ríos-Moreno A, Quesada-Moraga E (2016) Transient endophytic colonizations of plants improve the outcome of foliar applications of mycoinsecticides against chewing insects. J Invertebr Pathol 136:23-31

Ríos-Moreno A, Quesada-Moraga E, Garrido-Jurado I (2018) Treatments with Metarhizium brunneum BIPESCO5 and EAMa 01/58Su strains (Ascomycota: Hypocreales) are low risk for the generalist predator Chrysoperla carnea. J Pest Sci 91:385-394

Roy HE, Pell JK (2000) Interactions between entomopathogenic fungi and other natural enemies: implications for biological control. Biocontrol Sci Technol 10:737-752

Roy HE, Pell JK, Clark SJ, Alderson PG (1998) Implications of predator foraging on aphid pathogen dynamics. J Invertebr Pathol 71:236-247

Roy HE, Brown P, Rothery P, Ware RL, Majerus MEN (2008) Interactions between the fungal pathogen Beauveria bassiana and three species of coccinellid: Harmonia axyridis, Coccinella septempunctata and Adalia bipunctata. Biocontrol 53:265-276

Sampaio MV, Bueno VHP, De Conti BF (2008) The effect of the quality and size of host aphid species on the biological characteristics of Aphidius colemani (Hymenoptera: Braconidae: Aphidiinae). Eur J Entomol 105:489-494

Sánchez-Rodríguez AR, Del Campillo MC, Quesada-Moraga E (2015) Beauveria bassiana: an entomopathogenic fungus alleviates $\mathrm{Fe}$ chlorosis symptoms in plants grown on calcareous substrates. Sci Hortic 197:193-202
Shrestha G, Enkegaard A, Reddy GVP, Skovgård H, Steenberg T (2017) Susceptibility of larvae and pupae of the aphid parasitoid Aphelinus abdominalis (Hymenoptera: Aphelinidae) to the entomopathogenic fungus Beauveria bassiana. Annu Entomol Soc Am 110:121-127

Shrivastava G, Ownley BH, Augé RM, Toler H, Dee M, Vu A, Köllner TG, Chen F (2015) Colonization by arbuscular mycorrhizal and endophytic fungi enhanced terpene production in tomato plants and their defense against an herbivorous insect. Symbiosis 65:65-74

Sigsgaard L (2005) Oviposition preference of Anthocoris nemoralis and A. nemorum (Heteroptera: Anthocoridae) on pear leaves affected by leaf damage, honeydew and prey. Biocontrol Sci Technol 15:139-145

Simelane DO, Steinkraus DC, Kring TJ (2008) Predation rate and development of Coccinella septempunctata $\mathrm{L}$. influenced by Nezygites fresenii-infected cotton aphid prey. Biol Control 44:128-135

Smith RF (1978) History and complexity of integrated pest management. In: Smith EH, Pimentel D (eds) Pest control strategies. Academic Press, New York, pp 41-53

Smith SF, Krischik VA (2000) Effects of biorational pesticides on four coccinellid species (Coleoptera: Coccinellidae) having potential as biological control agents in interiorscapes. J Econ Entomol 93:732-736

Stern VM, Smith RF, van den Bosch R, Hagen KS (1959) The integrated control concept. Hilgardia 29:81-101

Todorova SI, Cote JC, Coderre D (1996) Evaluation of the effects of two Beauveria bassiana (Balsamo) Vuillemin strains on the development of Coleomegilla maculata lengi Timberlake (Col, Coccinellidae). J Appl Entomol 120:159-163

Vega FE (2018) The use of fungal entomopathogens as endophytes in biological control: a review. Mycologia 110:4-30

Vega FE, Goettel MS, Blackwell M, Chandler D, Jackson MA, Keller S, Pell JK (2009) Fungal entomopathogens: new insights on their ecology. Fungal Ecol 2:149-159

Wraight SP (2003) Synergism between insect pathogens and entomophagous insects and its potential to enhance biological control efficacy. In: Koul O, Dhaliwal GS (eds) Advances in biopesticide research (vol 3) predators and parasitoids. Taylor \& Francis, New York, pp 139-161

$\mathrm{Xu} \mathrm{H}$, Turlings TCJ (2018) Plant volatiles as mate finding cues for insects. Trends Plant Sci 23:100-111

Zehnder G, Gurr GM, Kühne S, Wade MR, Wratten SD, Wyss E (2007) Arthropod pest management in organic crops. Annu Rev Entomol 52:57-80

Publisher's Note Springer Nature remains neutral with regard to jurisdictional claims in published maps and institutional affiliations. 